\title{
In vitro cytokine profiles and viability of different human cells treated with whole cell lysate of Mycobacterium avium subsp. paratuberculosis
}

\author{
Pittu Sandhya Rani ${ }^{{ }^{*}}$, Nikhil Kumar Tulsian ${ }^{1}$, Leonardo A Sechi ${ }^{2}$ and Niyaz Ahmed ${ }^{1,3^{*}}$
}

\begin{abstract}
Mycobacterium avium subsp. paratuberculosis (MAP) is a zoonotic pathogen, a very slow growing bacterium which is difficult to isolate and passage in conventional laboratory culture. Although its association with Johne's disease or paratuberculosis of cattle is well established, it has been only putatively linked to Crohn's disease in humans. Further, MAP has been recently suggested to be a trigger for other autoimmune diseases such as type-1 diabetes mellitus (T1DM). Recently, some studies have indicated that exposure to MAP is associated with elevated levels of antibodies against MAP lysate although the exact mechanism and significance of the same remains unclear.

Further, the cytokine profiles relevant in MAP associated diseases of humans and their exact role in the pathophysiology are not clearly known. We performed in vitro cytokine analyses after exposing different cultured human cells to the whole cell lysate of MAP and found that MAP lysate induces secretion of cytokines IL-1 $\beta$, IL-6, IL-8, IL-10 and TNF-a by human peripheral blood mononuclear cells (PBMCs). Also, it induces secretion of IL-8 by cultured human stomach adenocarcinoma cells (AGS) and PANC-1(human pancreatic carcinoma cell line) cells. We also found that MAP lysate induced cytotoxicity in PANC-1 cells. Collectively, these results provide a much needed base-line data set of cytokines broadly signifying a MAP induced cellular response by human cells.
\end{abstract}

\section{Introduction}

Mycobacterium avium subsp. paratuberculosis (MAP) causes chronic inflammation of intestines in cattle and other ruminants, known as Johne's disease (JD) [1]. MAP infection in JD leads to an early proinflammatory and cytotoxic response (Th-1 like) that further escalates to a predominant antibody based immune response (Th-2 like). Furthermore, studies have demonstrated that MAP infected cattle show enhanced IL-8 gene expression in intestinal tissues when compared to controls [2]. Studies on ovine macrophages indicated that MAP can induce low level apoptosis but not cytotoxicity (necrosis) [3]. MAP, an obligate zoonotic pathogen is also linked to a similar type of enteritis as JD, in humans, known as Crohn's disease [4,5], wherein, the symptoms include abdominal pain, ulcers and diarrhoea (with bloody episodes) [6]. Moreover, this disease is also considered as

\footnotetext{
* Correspondence: sandhyarani317@gmail.com; ahmed.nizi@gmail.com 'Pathogen Biology Laboratory, Department of Biotechnology, School of Life Sciences, University of Hyderabad, Hyderabad, India

${ }^{3}$ Institute of Biological Sciences, University of Malaya, Kuala Lumpur, Malaysia Full list of author information is available at the end of the article
}

an autoimmune disorder with inflammation contributed by Th1 cytokine responses [7]. Studies have also suggested that Crohn's disease might have a genetic link such as mutation in the NOD2 gene [8]. The epidemiological studies have indicated that Crohn's disease is more common in the temperate regions of the globe with intensive farming [9]. Diseased animals with clinical JD may shed MAP in their milk and faeces, and it is observed that MAP resists chlorination and pasteurization [10]. The existence of MAP in sphaeroplast form in addition to its bacillary form ensures survival [11]. ELISA studies have indicated correlation between MAP infection and type 1 diabetes mellitus (T1DM) [12,13]. It has been reported that children exposed to MAP in early life have low incidence of certain autoimmune diseases and exposure to MAP is associated with raised antibody levels against MAP [14-16].

In both cattle and humans, there is a long delay between the MAP infection and occurrence of the clinical disease. The clinical manifestation could ultimately be the outcome of various cytokine responses of an activated 
immune system unable to effectively control the infection [17]. Both Crohn's disease and Type 1 diabetes are characterized by inflammatory responses, and, genetic predisposition alone cannot explain their acquisition. Several factors such as gut microflora, pathogens, dietary elements and environmental toxins are being considered in the development of these diseases although MAP has emerged as an important microbial trigger.

Given some association studies that putatively link MAP to T1DM or Crohn's, not many efforts have been directed at identifying the cytokine profiles pathognomonic of MAP infection in humans. In this preliminary study we were interested to analyze cytokine coordinates relevant to chronic autoimmune disease pathology by in vitro studies of different human cells after treatment with whole cell lysate of MAP.

\section{Results and discussion Responses of the PBMCs}

We performed a set of experiments including cytokine analysis with MAP lysates. These included the treatment of human PBMCs with MAP lysate that resulted in an increased secretion of cytokines IL-1 $\beta$, IL-6, IL-8, IL-10 and TNF- $\alpha$ in a dose and time dependent manner (Figure 1A). The cytokine responses from the human PBMCs were from two normal humans who presumably have not been exposed to MAP. Hence the cytokine responses were the innate ones. We do believe that these PBMCs may not be naïve to the mycobacterial antigens either because BCG vaccination is a normal practice in India or due to a saprophytic mycobacterial exposure. This could be one of the possible reasons as to why the PBMCs revealed highly significant cytokine responses.

\section{Responses of the cell lines}

Treatment of AGS cells and PANC-1 cells with MAP lysate resulted in increased secretion of IL-8 in a dose and time dependent manner (Figure $1 \mathrm{~B}$ and Figure $1 \mathrm{C}$ ), but, secretion of other cytokines was not observed (data not shown). IL-8 is a chemotactic factor that mediates recruitment and activation of the cells of inflammation in the lesions of various types of inflammatory processes [18]. TNF- $\alpha$ and IL-1 $\beta$ are involved in Th- 1 response; IL-10 is involved with Th-2 response. Although, IL-6 mediates acute phase response but when its function persists as proinflammatory cytokine, then acute inflammation turns into a chronic one. Further, in autoimmune disorders, IL-6 is not only involved in the maintenance of inflammation but also in modification of the immune responses [19]. These points suggest that MAP lysate activates both Th- 1 and Th- 2 responses. TNF- $\alpha$ secreted by macrophages induces inflammation; increased levels of TNF- $\alpha$ have been found to be associated with the development of Crohn's disease [20]. Further, significantly higher concentrations of TNF- $\alpha$ were found in MAP-positive Crohn's disease patients [21]. Plasma concentration of IL-6 was significantly high in patients with Crohn's disease when compared to healthy controls [22]. Previous studies have shown that monocytes isolated directly from the blood of T1DM individuals secreted proinflammatory cytokines such as IL-1 $\beta$ and IL-6 thereby triggering the expansion of Th17 cells that are intimately involved in the development of autoimmune diseases [23]. Nevertheless, in patients with recent onset of T1DM and also in animal models of T1DM, increased expression of TNF- $\alpha$ and IL- $1 \beta$ was observed in pancreas [24]. We do not believe that the observed cytokine responses could be due to other confounding triggers (such as Mycobactin J used in bacterial culture media or the foetal bovine serum used in cell culture), as we have taken enough care to ensure fool proof protocols and ensured essential centrifugation and washing steps to move away any residual media or living bacterial cells.

\section{Cytotoxic effects of the MAP lysate}

To determine the possible cytotoxic effects of MAP lysate, we performed MTT assay with human PBMCs, AGS cells and PANC-1 cells after treatment with MAP lysate. The results indicated that MAP lysate caused no cytotoxic effects to the human PBMCs and AGS cells (Figure 2A and Figure 2B). However, when PANC-1 cells were treated with MAP lysate, no cytotoxic effect was observed up to $48 \mathrm{hr}$, but, a dose dependent cytotoxic effect was observed at 72 and $96 \mathrm{hr}$ (Figure 2C). This was further confirmed by DAPI staining of PANC-1 cells on treatment with MAP lysate; this observation indicates cell membrane rupture representing necrosis (Figure 3). In view of these findings, we believe that MAP lysates exert differential effect on different types of epithelial cells i.e. AGS and PANC-1 cells. Further, cell viability was not affected in all the cell types when MTT assay was performed after treatment with other mycobacterial cell lysates such as the crude antigen preparation of Mycobacterium smegmatis (data not shown).

\section{Conclusions and prospective}

Taken together, these observations portray cytokine coordinates of the treatment of cultured human cells with MAP lysate which were documented for diverse cell types using cytometry and imaging experiments. MAP lysate induced dose and time dependent cytotoxicity in PANC-1 cells. Further, we found whole cell lysate preparation to be an important 'global' antigen to perform cytokine assays probably indicative of the cellular responses of mammalian cells rather than employing individual MAP proteins to interact with cultured cells. The latter is both 


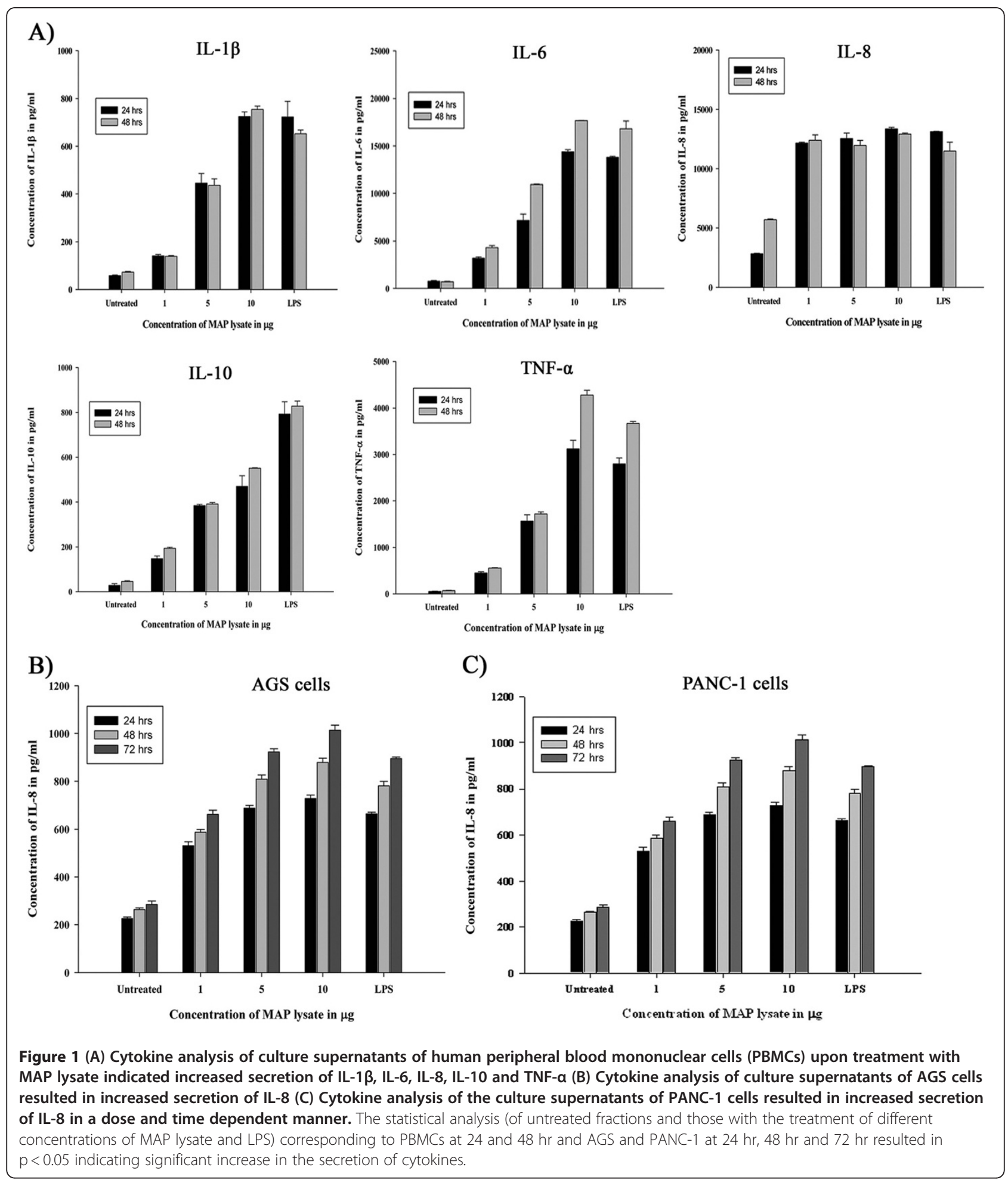

reductive and a time consuming proposal. Having this said, some issues remain. It is difficult to ascertain if the responses of MAP lysate-treated cells represent what occurs in vivo in MAP-associated diseases. Are these observations unique to MAP lysates? What are the bioactive components responsible for the observed response? Is the same response induced when the gut is challenged with MAP or the crude MAP preparations used for immunization? Although we do not have full answers to these obvious questions, it will be possible to 


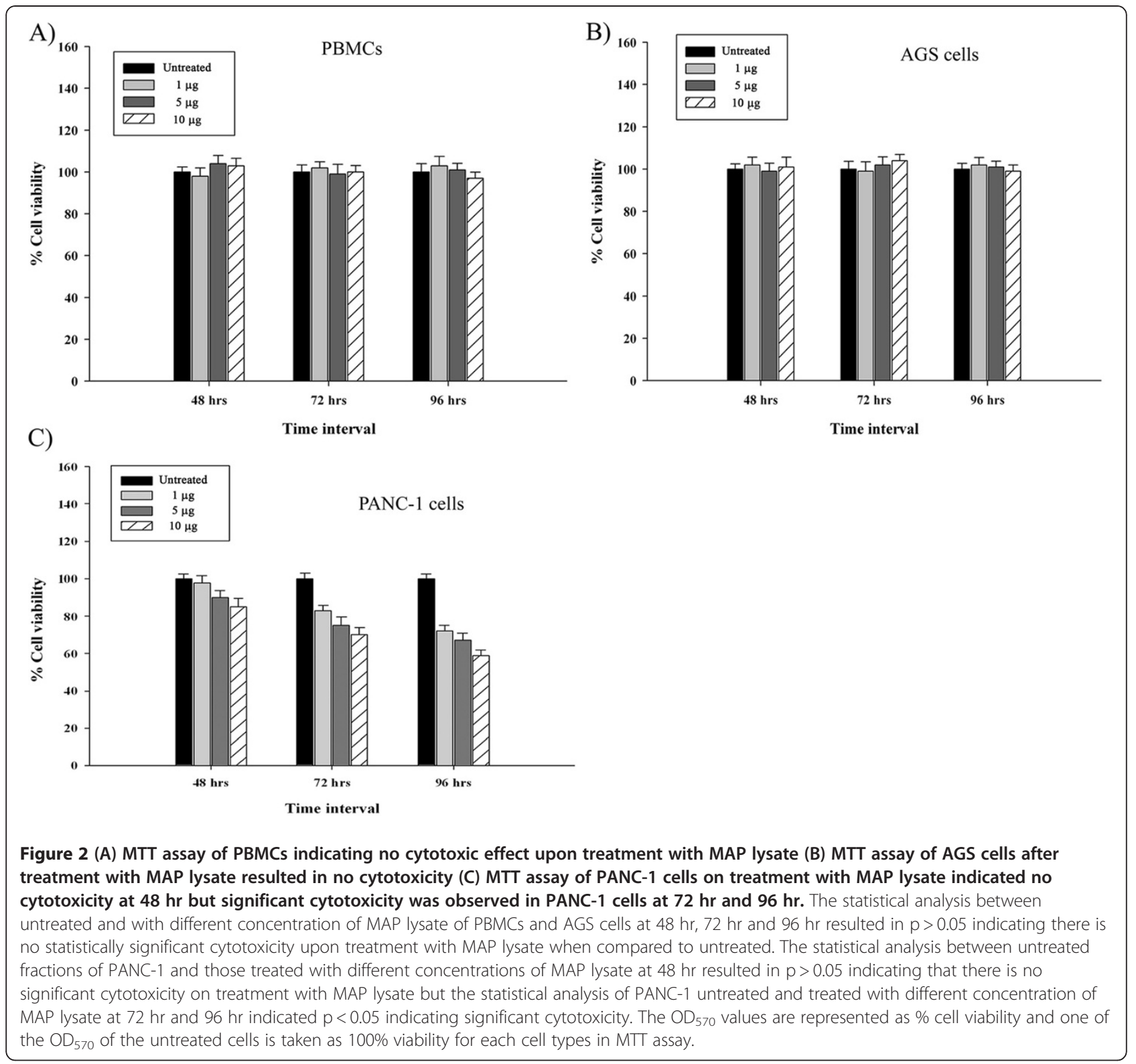

continue work on these lines to come up with a more robust in vitro model of MAP infection in the near future.

\section{Materials and methods}

\section{Ethics statement}

This study did not entail any specific ethical approvals although informed consents were obtained from the 2 healthy donors of the human peripheral blood mononuclear cells (PBMCs).

\section{Preparation of MAP lysate}

The MAP strain 1515(ATCC43015) was cultured in 7 H9 medium (Sigma-Aldrich) supplemented with 10\% ADC (albumin dextrose catalase), $0.05 \%$ Tween80 (SigmaAldrich). and Mycobactin J (2 $\mu \mathrm{g} / \mathrm{ml})$ and incubated at $37^{\circ} \mathrm{C}$ until an approximate OD of 500 was achieved. The culture was then centrifuged at $4000 \mathrm{~g}$ for $20 \mathrm{~min}$ and the cell pellet washed twice with 1 XPBS. The cells were subjected to disruption on ice by using ultrasonic homogenizer. The resultant lysate was then centrifuged at $10000 \times \mathrm{g}$ for $20 \mathrm{~min}$ to remove unbroken cells and cell debris. The supernatant was decanted and transferred into a fresh tube. The protein concentration was determined by Bradford's reagent.

Cytokine analysis of human PBMCs, AGS and PANC-1 cells The heparinised blood was collected from two healthy individuals and PBMCs were isolated from the method previously described [25]. A total of about 0.5 million cells per ml of RPMI1640 media (Hyclone) containing 

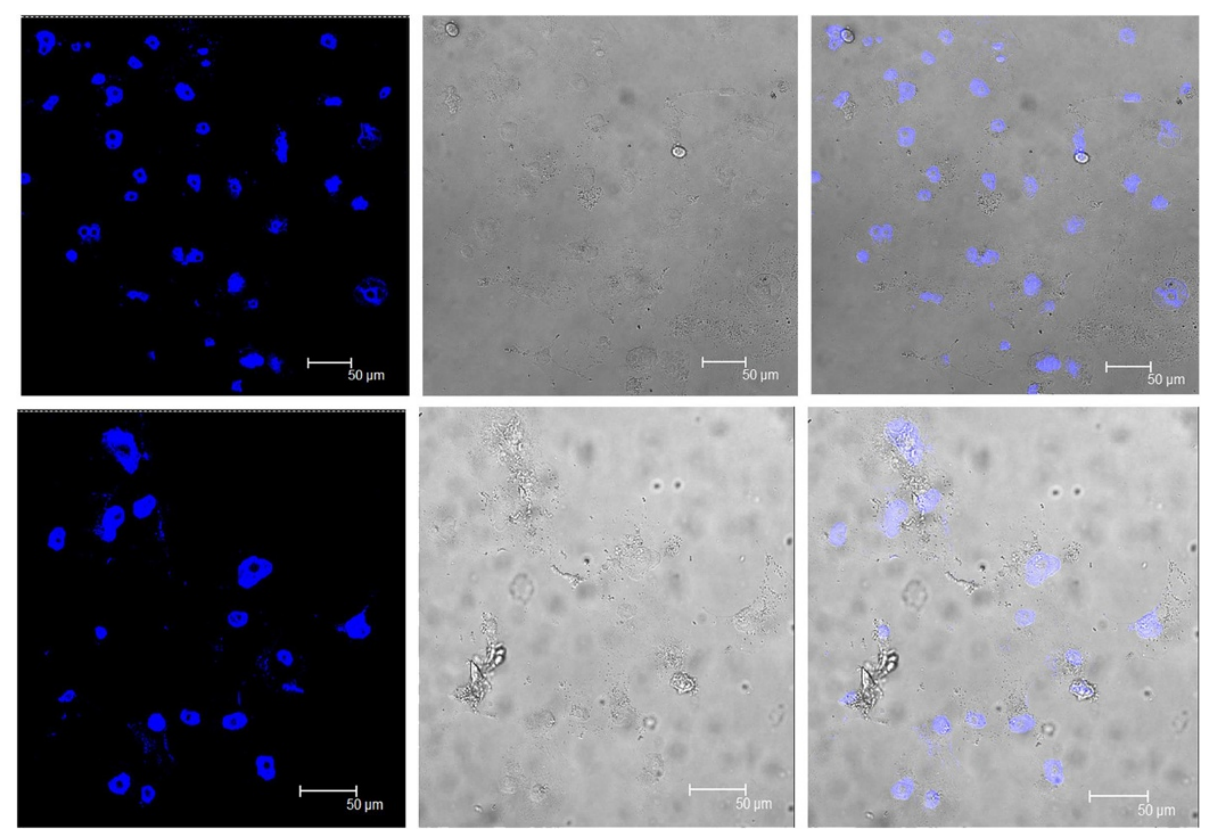

Figure 3 DAPI stained PANC-1 cells on treatment with MAP lysate indicated cell membrane rupture representing necrosis when compared to untreated PANC-1 cells.

$10 \%$ foetal bovine serum (FBS) (Hyclone) were treated with different concentrations of MAP lysate $(1 \mu \mathrm{g}, 5 \mu \mathrm{g}$, $10 \mu \mathrm{g})$ as compared to treatment by $1 \mu \mathrm{g}$ of $E$. coli LPS (Sigma) used as a positive control. The culture supernatants were collected at 24 and $48 \mathrm{hr}$ respectively and were stored at $-80^{\circ} \mathrm{C}$ until the cytokine analysis was performed. A total of 0.5 million AGS cells (NCCS, Pune, India) per ml of HAMS F-12 media (Hyclone) containing 10\% FBS and 0.5 million of PANC-1 cells (ATCC) per $\mathrm{ml}$ of DMEM high glucose (Hyclone) media containing 10\% FBS were treated with different concentrations of MAP lysate $(1 \mu \mathrm{g}, 5 \mu \mathrm{g}, 10 \mu \mathrm{g})$ and with $1 \mu \mathrm{g}$ of LPS (positive control). The culture supernatants were collected at 24, 48 and $72 \mathrm{hr}$ in each case and stored at $-80^{\circ} \mathrm{C}$ until the cytokine analysis was performed. The cytokines IL-1 $\beta$, IL-6, IL-8, IL-10, and TNF- $\alpha$ in the culture supernatants were analysed by BD CBA flex kit (BD Biosciences, USA). The acquisition of the sample was carried out in a BD FACS Canto II flow cytometer by using BD FACS diva software and the analysis was carried out by plotting the standard curve for each cytokine by using FCAP array software (Soft Flow/BD Biosciences).

\section{MTT (3-(4, 5-Dimethylthiazol-2-yl)-2, 5-diphenyl} tetrazolium bromide) assay of PBMCs, AGS and PANC-1 cells upon treatment with MAP lysate

A total of about 0.05 million cells of human PBMCs per $200 \mu \mathrm{l}$ of RPMI1640 media (Hyclone) containing 10\%
FBS (Hyclone), 0.05 million AGS cells per $200 \mu \mathrm{l}$ of HAMS F-12 media (Hyclone) containing 10\% FBS (Hyclone) and 0.05 million PANC-1 cells per $200 \mu \mathrm{l}$ of DMEM High glucose (Hyclone) containing 10\% FBS (Hyclone) were treated with different concentrations $(1 \mu \mathrm{g}, 5 \mu \mathrm{g}, 10 \mu \mathrm{g})$ of MAP lysate. MTT assay was carried out after 48, 72 and $96 \mathrm{hr}$ respectively. To the cells containing media, $50 \mu \mathrm{l}$ of $5 \mathrm{mg} / \mathrm{ml}$ of MTT (Sigma) was added and incubated at $37^{\circ} \mathrm{C}$ for $4 \mathrm{hr}$. Then the plate was centrifuged at $2000 \mathrm{rpm}$ for $10 \mathrm{~min}$. The supernatant was discarded and $200 \mu \mathrm{l}$ of $40 \mathrm{mM}$ acidified isopropanol was added and incubated at $37^{\circ} \mathrm{C}$ for $15 \mathrm{~min}$. The purple color thus formed was measured at $570 \mathrm{~nm}$ in ELISA reader (infinite M200 TECAN).

\section{DAPI (4', 6-diamidino-2-phenylindole) staining of PANC-1 cells}

A total of about 0.05 million of PANC-1 cells were grown on the cover slip and treated with $10 \mu \mathrm{g}$ MAP lysate for $72 \mathrm{hr}$. The media from untreated cells and treated cells was removed and the cells washed with $1 \mathrm{X}$ PBS. The cells were then fixed by treatment with $4 \%$ paraformaldehyde and incubated for $15 \mathrm{~min}$ at $37^{\circ} \mathrm{C}$. The cells were then washed thrice with $1 \mathrm{X}$ PBS. The cells were subsequently treated for $15 \mathrm{~min}$ at $37^{\circ} \mathrm{C}$ with $0.2 \%$ Triton-X 100 in PBS to induce permeability. The cells were then washed thrice with $1 \mathrm{X}$ PBS. DAPI with antifade reagent was subsequently added to the cells on the coverslip. The coverslip was then carefully reverted 
on to the clean glass slide and placed for observation under a fluorescence microscope (Leica).

\section{Statistical analysis}

The student's $t$-test was performed using Graph pad Prism 5.0 software. The $p$-value was calculated for each experiment which was conducted in triplicates.

\section{Competing interests}

The authors declare that they have no competing interests.

\section{Authors' contributions}

PSR and NKT performed the experiments, analyzed results and wrote the draft manuscript. NA provided laboratory facilities and resources for the study and contributed to the discussions. LAS generated MAP lysates and provided suggestions for the interpretation of the results. All authors read and approved the final manuscript.

\section{Acknowledgement}

This and other related research in Ahmed lab was funded through a grant from the Department of Biotechnology (DBT) of the Indian Government (No. BT/PR8040/Med/14/1224/2006) and partly through the University of Malaya HIR Grant (UM.C/625/1/HIR/MOHE/CHAN-02). PSR received a Senior Research Fellowship from the DBT. We are thankful to the two healthy volunteers for the use of PBMCs under informed consent.

\section{Author details}

'Pathogen Biology Laboratory, Department of Biotechnology, School of Life Sciences, University of Hyderabad, Hyderabad, India. ${ }^{2}$ Department of Biomedical Sciences, University of Sassari, Sassari, Italy. Institute of Biological Sciences, University of Malaya, Kuala Lumpur, Malaysia.

Received: 2 February 2012 Accepted: 10 September 2012 Published: 24 September 2012

\section{References}

1. Chiodini RJ, Van Kruiningen HJ, Merkal RS: Ruminant paratuberculosis (Johne's disease): the current status and future prospects. Cornell Vet 1984, 74:217-226.

2. Coussens PM, Verman N, Coussens MA, Elftman MD, McNulty AM: Cytokine gene expression in peripheral blood mononuclear cells and tissues of cattle infected with mycobacterium avium subsp. Paratuberculosis: evidence for an inherent proinflammatory gene expression pattern. Infect Immun 2004, 72:1409-1422.

3. Berger ST, Griffin FT: A comparison of ovine monocyte-derived macrophage function following infection with mycobacterium avium ssp. Avium and mycobacterium avium ssp. Paratuberculosis. Immunol Cell Biol 2006, 84:349-356.

4. Naser SA, Ghobrial G, Romero C, Valentine JF: Culture of mycobacteriumavium subspecies paratuberculosis from the blood of patients with Crohn's disease. Lancet 2004, 364:1039-1044.

5. Sechi LA, Scanu AM, Molicotti P, Cannas S, Mura M, Dettori G, Fadda G, Zanetti S: Detection and isolation of mycobacterium avium subspecies paratuberculosis from intestinal mucosal biopsies of patients with and without Crohn's disease in Sardinia. Am J Gastroenterol 2005, 100:1529-1536.

6. Taylor JH, Bull T: Crohn's Disease caused by mycobacterium avium subspecies paratuberculosis: a public health tragedy whose resolution is long overdue. J Med Microbiol 2002, 51:3-6.

7. Cobrin GM, Abreu MT: Defects in mucosal immunity leading to Crohn's disease. Immunol Rev 2005, 206:277-295.

8. Ogura Y, Bonen DK, Inohara N, Nicolae DL, Chen FF, Ramos R, Britton H, Moran T, Karaliuskas R, Duerr RH, Achkar JP, Brant SR, Bayless TM, Kirschner BS, Hanauer SB, Nunez G, Cho JH: A frameshift mutation in NOD2 associated with susceptibility to Crohn's disease. Nature 2001, 411:603-606

9. Kyle J: Crohn's disease in the northeastern and northern Isles of Scotland: an epidemiological review. Gastroenterology 1992, 103:392-399.
10. Pierce E: Possible transmission of mycobacterium avium subspecies paratuberculosis through potable water: lesson from an urban cluster of Crohn's disease. Gut Pathog 2009, 1:17.

11. Rowe MT, Grant IR: Mycobacterium avium subsp. paratuberculosis and its potential survival tactics. Lett Appl Microbiol 2006, 42:305-311.

12. Rani PS, Sechi LA, Ahmed N: Mycobacterium avium subsp. paratuberculosis as a trigger of type-1 diabetes: destination Sardinia, or beyond? Gut Pathogens 2010, 2:1.

13. Sechi LA, Rosu V, Pacifico A, Fadda G, Ahmed N, Zanetti S: Humoral immune responses of type 1 diabetes patients to mycobacterium avium subsp. Paratuberculosis lend support to the infectious trigger hypothesis. Clin Vaccine Immunol 2008, 15:320-326.

14. Radon K, Windstetter D, Poluda AL, Mueller B, Mutius EV, Koletzko S, Tieren CAK, (Chronic Autoimmune Disease and Animal Contact) Study Group: Contact with farm animals in early life and juvenile inflammatory bowel disease: a case-control study. Pediatrics 2007, 120:354-361.

15. Chiodini RJ, Thayer WR, Coutu JA: Presence of mycobacterium paratuberculosis antibodies in animal healthcare workers. In Proceedings of the fifth international colloquium on paratuberculosis 1996. Edited by Chiodini RJ, Hines ME, Collins MT, Rehoboth MA. Madison, Wisconsin USA: International Association of Paratuberculosis; 1996:324-328.

16. Gerstein HC: Cow's milk exposure and type I diabetes mellitus - a critical overview of the clinical literature. Diabetes Care 1994, 17:13-19.

17. Chamberlin W, Graham DY, Hulten K, El-zimaity HMT, Schwartz MMR, Naser S, Shafran I, El-zaatari FAK: Mycobacterium avium subsp paratuberculosis as one cause of Crohn's disease. Aliment Pharmacol Ther 2001, 15:337-346.

18. Harada A, Sekido N, Akahoshi T, Wada T, Mukaida N, Matsushima K: Essential involvement of interleukin-8 (IL-8) in acute inflammation. J Leukoc Biol 1994, 6:559-564.

19. Gabay C: Interleukin-6 and chronic inflammation. Arthritis Res Ther 2006, 2(8Suppl):S3.

20. Behm BW, Bickston SJ: Tumor necrosis factor-alpha antibody for maintenance of remission in Crohn's disease. Cochrane Database Syst Rev 2008, 1:CD006893.

21. Clancy R, Ren Z, Turton J, Pang G, Wettstein A: Molecular evidence for mycobacterium avium subspecies paratuberculosis (MAP) in Crohn's disease correlates with enhanced TNF-a secretion. Dig Liver Dis 2007, 39:445-451.

22. Mahida YR, Kurlac L, Gallagher A, Hawkey CJ: High circulating concentrations of interleukin- 6 in active Crohn's disease but not ulcerative colitis. Gut 1991, 32:1531-1534.

23. Bradshaw EM, Raddassi K, Elyaman W, Orban T, Gottlieb PA, Kent SC, Hafler DA: Monocytes from patients with type 1 diabetes spontaneously secrete proinflammatory cytokines inducing Th17 cells. J Immunol 2009, 183:4432-4439.

24. Uno S, Imagawa A, Okita K, Sayama K, Moriwaki M, Iwahashi H, Yamagata K, Tamura S, Matsuzawa Y, Hanafusa T, Miyagawa J, Shimomura I: Macrophages and dendritic cells infiltrating islets with or without $\beta$-cells produce tumour necrosis factor- $\alpha$ in patients with recent-onset type 1 diabetes. Diabetologia 2007, 50:596-601.

25. Boyum A: Separation of blood leucocytes, granulocytes and lymphocytes. Tissue Antigens 1974, 4:269-274.

doi:10.1186/1757-4749-4-10

Cite this article as: Rani et al: In vitro cytokine profiles and viability of different human cells treated with whole cell lysate of Mycobacterium avium subsp. paratuberculosis. Gut Pathogens 2012 4:10. 